\title{
A Chlamydia trachomatis strain with a chemically generated amino acid substitution (P370L) in the cthtrA gene shows reduced elementary body production
}

\author{
James W. Marsh', Bryan A. Wee', Joel D.A. Tyndall², William B. Lott', Robert J. Bastidas ${ }^{3}$, Harlan D. Caldwell',
} Raphael H. Valdivia ${ }^{3}$, L. Kari ${ }^{4}$ and Wilhelmina M. Huston ${ }^{1 *}$

\begin{abstract}
Background: Chlamydia (C.) trachomatis is the most prevalent bacterial sexually transmitted infection worldwide and the leading cause of preventable blindness. Genetic approaches to investigate $C$. trachomatis have been only recently developed due to the organism's intracellular developmental cycle. HtrA is a critical stress response serine protease and chaperone for many bacteria and in C. trachomatis has been previously shown to be important for heat stress and the replicative phase of development using a chemical inhibitor of the CtHtrA activity. In this study, chemically-induced SNVs in the cthtrA gene that resulted in amino acid substitutions (A240V, G475E, and P370L) were identified and characterized.
\end{abstract}

Methods: SNVs were initially biochemically characterized in vitro using recombinant protein techniques to confirm a functional impact on proteolysis. The C. trachomatis strains containing the SNVs with marked reductions in proteolysis were investigated in cell culture to identify phenotypes that could be linked to CtHtrA function.

Results: The strain harboring the SNV with the most marked impact on proteolysis (cthtr $A_{p 370 L}$ ) was detected to have a significant reduction in the production of infectious elementary bodies.

Conclusions: This provides genetic evidence that CtHtrA is critical for the C. trachomatis developmental cycle.

Keywords: Chlamydia, HtrA, Genetics, Heat shock, Intracellular

\section{Background}

Chlamydia trachomatis is the most prevalent bacterial sexually transmitted infection worldwide and the leading cause of preventable blindness $[1,2]$. If left untreated, chlamydial infection can lead to serious and costly conditions including infertility, ectopic pregnancy, epididymitis, and pelvic inflammatory disease. As intracellular bacteria, the Chlamydiae are defined by their unique development cycle where small, infectious elementary bodies (EB) invade a host cell and differentiate into large, non-infectious reticulate bodies (RB) that replicate by binary fission [3]. Due to the absence of several biosynthesis pathways that

\footnotetext{
* Correspondence: w.huston@qut.edu.au

'Institute of Health and Biomedical Innovation (IHBI), Queensland University of Technology (QUT), 60 Musk Avenue, Kelvin Grove, QLD 4059, Australia Full list of author information is available at the end of the article
}

are common to most other bacteria, Chlamydia has a reduced genome size $(\sim 1 \mathrm{Mb})$ that requires the organism to rely on the host cell for nutrients and survival [4]. As a result, Chlamydia's obligate intracellular development cycle had hampered progress towards genetic techniques and the organism's pathogenic mechanisms have not been fully elucidated.

HtrA is a critical protease and chaperone for many bacteria and has been implicated in several functions including stress response, protein quality control, outer membrane protein (OMP) localization and assembly, host cell manipulation, and virulence [5-9]. The distinct biochemical functions of proteolysis and chaperone activity are mediated by the allosteric activation of the protein to oligomers ranging from trimers to hexamers to at least 24-mers [7, 10]. Using homology modeling and biochemical methods, we have 
previously suggested that $C$. trachomatis $\mathrm{HtrA}$ (CtHtrA) proteolytic activation and oligomerization are mediated by distinct structural pathways, and that specificity of the substrate binding may differentiate protease and chaperone activity $[11,12]$. HtrA is highly conserved in Chlamydia and the application of a chemical inhibitor of $C t \mathrm{HtrA}$ protease activity indicated that $C t \mathrm{HtrA}$ is important for the replicative phase of the chlamydial developmental cycle, important for the recovery from penicillin-induced chlamydial persistence, and has a critical role during heat stress [13-18]. These data, relying on both biochemical and inhibitor-based approaches, enabled significant insight into $C t \mathrm{HtrA}$ function and the role of specific parts of the amino acid sequence for these functions, and provided the foundation for this attempt to use genetics to investigate $C t \mathrm{HtrA}$ 's physiological role for C. trachomatis.

In the absence of genetic techniques such as targeted gene replacement and transposon-based mutagenesis, the field has instead relied on genomic, proteomic, and transcriptomic methods for chlamydial research. However, functional validation requires genetic evidence. In response, several molecular strategies have recently proven successful including small molecule inhibitors $[15,19]$, random chemical mutagenesis [20], lateral gene transfer [21], and shuttle vector transformations [22]. Given our existing data on the structure and function of $\mathrm{C} t \mathrm{HtrA}$, genetic approaches such as random chemical mutagenesis are a promising approach to for the characterisation of $C t \mathrm{HtrA}$ in C. trachomatis.

Chemical mutagenesis is the use of chemical compounds to increase the frequency of chromosomal mutations above the spontaneous rate [23]. The types of DNA lesions produced include DNA adducts, intercalation, inter-strand cross-linking, alkylation, and/or base modifications, which result in base-pair substitutions, frameshift mutations, and/ or deletions in the nucleotide sequence. In 2011, Kari et al. presented the development of a reverse genetics approach using chemical mutagenesis to generate isogenic mutants of C. trachomatis [24], demonstrating that EMS is a viable mutagen for genetic studies in Chlamydia. EMS is an alkylating agent that specifically acts at nitrogen positions in nucleotide bases to produce GC to AT transition mutations [25]; based on the GC content of the C. trachomatis L2 434/Bu genome, there are 429,520 potential sites that could theoretically be mutated by EMS. Thus, single nucleotide variants (SNV), induced by the EMS treatment of C. trachomatis, can be identified in a gene of interest and subjected to a genetic characterization of its function. Given our awareness of the residues and structural elements that are important for CtHtrA's protease and chaperone activity [11, 12, 17, 18], we investigated several SNVs in the cthtrA gene to examine the protein's physiological function for C. trachomatis.

\section{Methods}

\section{Chlamydial culture conditions}

Chlamydia trachomatis was routinely cultured in McCoy B or HEp-2 cells in the presence of DMEM supplemented with $10 \%$ fetal calf serum (FCS) at $37^{\circ} \mathrm{C}, 5 \%$ $\mathrm{CO}_{2}$. Experiments were typically conducted at an MOI of 0.3 . For the calculation of infectious yield, cultures harvested in SPG buffer (10 mM sodium phosphate, $250 \mathrm{mM}$ sucrose, $5 \mathrm{mM}$ glutamic acid, $\mathrm{pH}$ 7.4) were serially diluted and cultured in fresh McCoy B cell monolayers until $30 \mathrm{~h}$ post-infection, when they were fixed with methanol and stained for microscopy. The infectious yield was determined by the number of inclusion forming units from each milliliter of the original culture.

\section{Chemical mutagenesis}

Chemical mutagenesis of $C$. trachomatis L2 was performed by the Valdivia Laboratory at Duke University, NC, USA [21]. Vero cells were infected with $\mathrm{Rif}^{\mathrm{R}} \mathrm{C}$. trachomatis serovar LGV biovar L2 434/Bu at an MOI of 5.0 for $18 \mathrm{~h}$ and exposed to $20 \mathrm{mg} / \mathrm{mL}$ ethyl methanesulfonate (EMS) in PBS for $1 \mathrm{~h}$, as described [21]. EMS was prepared in phosphate buffered saline (PBS) with $0.9 \mathrm{mM}$ calcium chloride and $0.49 \mathrm{mM}$ magnesium chloride [26]. The cells were washed three times in $\mathrm{PBS}+\mathrm{CaCl}_{2} / \mathrm{MgCl}_{2}$ to remove residual mutagen and incubated in DMEM $/ 5 \%$ FCS at $37^{\circ} \mathrm{C}$ in a $5 \% \mathrm{CO}_{2}$ humidified incubator for $48-72 \mathrm{~h}$ to allow the bacteria to recover and complete their developmental cycle. EBs were harvested by hypotonic lysis of infected cells with sterile water, followed by addition of $5 \times$ SPG media to a final concentration of $1 \times$ SPG, titered for IFUs, plaque-purified as described [21] and stored at $-80{ }^{\circ} \mathrm{C}$. The frequency of mutagenesis was determined by inducing rifampicin resistance, followed by the plaque purification using $7 \times 10$-fold serial dilutions of bacteria in the presence of $200 \mathrm{ng} / \mathrm{mL}$ rifampicin [26]. The frequency of rifampicin resistance was defined as the number of rifampicinresistant plaques divided by the total number of bacteria plated [26]. C. trachomatis L2 chlamydial mutant strains containing SNVs in cthtrA were identified from whole genome sequences generated from a collection of 934 chemically mutagenized C. trachomatis L2 strains (sourced from the Valdivia laboratory for this study, investigated in the Huston Lab in Australia). Isolates from this collection containing $c$ thtr $A$ variants were further purified by plaque isolation (in Australia).

C. trachomatis D was mutagenized four consecutive times in the Caldwell Laboratory, NIAID Rocky Mountain Laboratories, Montana. At each round, infected McCoy cells were exposed to 5-7 mg/mL EMS $19 \mathrm{~h}$ post-infection for $1 \mathrm{~h}$ and chlamydiae were harvested 40-44 h post-infection. A library of sub-populations were built to screen for cthtrA mutants. McCoy B cells in 96-well tissue culture plates were infected with 8 
inclusion-forming units per well. Chlamydiae were harvested at $48 \mathrm{~h}$ post-infection and were used to reinfect McCoy B cells in 96-well tissue culture plates. Infected cells were harvested and passaged for a third time, and DNA extracted from the third passage was used to PCR amplify cthtrA. Amplicons were heat denatured, slowly reannealed, and digested by CEL I endonuclease. Digestion products were visualized by DNA agarose gel electrophoresis. Mutations detected by CEL I digestion were identified by Sanger sequencing (these strains and this work to identify the mutations was conducted in the Caldwell laboratory, characterization of the strains was conducted in the Huston laboratory).

\section{In silico analysis of cthtrA SNVs}

$C t$ HtrA sequence alignments, 2D structural motifs, and homology models for the hexameric and 24-meric oligomers were used for the characterisation of EMS mutants, as previously described [11]. Each mutation was examined in both oligomeric models of CtHtrA with the PyMOL Molecular Graphics System, Version 1.7.4 Schrödinger, LLC, according to secondary structure localisation and potential impact on $\mathrm{CtH}$ trA function.

\section{Site-directed mutagenesis and recombinant protein expression}

The previously generated $C t \mathrm{HtrA}$ recombinant expression construct was used for this study [17]. Site-directed mutagenesis was used to introduce point mutations corresponding to the EMS mutations identified in the chlamydial strains using a QuikChange II XL SiteDirected Mutagenesis Kit (Stratagene) using the primers A240Vsdm, E47Ksdm, G268Rsdm, G475Esdm, P370Lsdm, and R55Qsdm (Additional file 1: Table S4). All mutations were confirmed by Sanger sequencing. Heterologous recombinant protein expression and purification of $\mathrm{CtHtrA}$ recombinant mutated proteins were completed as previously published $[11,12,17]$.

\section{Protease assays}

Full-length $\beta$-casein cleavage assays were initially used to test the proteolytic activity of wild type $C t \mathrm{HtrA}$ and the mutants. Up to $2 \mathrm{mg}$ of recombinant $C t \mathrm{HtrA}$ was incubated with $10 \mathrm{mg}$ of $\beta$-casein in $50 \mathrm{mM}$ Tris, $20 \mathrm{mM}$ $\mathrm{MgCl}_{2}$ and examined with SDS-PAGE as previously described [17]. The gel bands were quantified by densitometry using a Li-Cor Odyssey 9120 Infrared Imaging System. The rate of proteolysis was tested with a peptide substrate labelled with 7-methoxycoumarin-4-acetic acid (MCA; fluorophore) and 2,4-dinitrophenyl (DNP; quencher) in black plates at $37{ }^{\circ} \mathrm{C}$ using a POLARstar Optima D77656 fluorimeter. Substrate specificity was examined using peptides labelled with para-Nitroanilide $(p \mathrm{NA})$ that were incubated with $\mathrm{CtH}$ trA at $37{ }^{\circ} \mathrm{C}$ and analysed with an xMARK microplate spectrophotometer. All protein and peptide substrates and allosteric activators are listed in Additional file 1: Table S5. All peptides and activators were synthesised by Mimotopes (Melbourne, VIC, Australia) to $95 \%$ purity and were resuspended in $50 \%$ isopropanol or DMSO. Statistical analyses were conducted using an unpaired $t$-test, calculated with Prism software. All assays were conducted on two separate occasions, in triplicate.

\section{Oligomerization assays}

The ability of $C t \mathrm{HtrA}$ or the mutants to oligomerize to higher oligomers was examined by crosslinking oligomers with glutaraldehyde as previously described [12]. The samples were separated on 3-8 \% Tris-Acetate gradient polyacrylamide gels and examined by silver staining. All assays were conducted in triplicate on three separate occasions. HiMark pre-stained molecular weight marker (Life Technologies, USA) was included on each gel.

\section{Heat shock of chlamydial culture}

Heat shock assays were performed by infecting HEp-2 cells in a 48-well plate with $C t \mathrm{~L} 2_{\text {wt }}$ and each mutant at an MOI of 0.3 in DMEM at $37{ }^{\circ} \mathrm{C}, 5 \% \mathrm{CO}_{2}$. Cultures were heat shocked for $4 \mathrm{~h}$ at $42{ }^{\circ} \mathrm{C}, 5 \% \mathrm{CO}_{2}$ beginning at $20 \mathrm{~h}$ post-infection, before returning the cultures to $37{ }^{\circ} \mathrm{C}$ for the remainder of the development cycle, prior to the measurement of infectious progeny [14].

\section{Chlamydia growth curves}

Growth curve assays were performed by infecting McCoy B cells in a 96-well plate with $C t \mathrm{~L} 22_{\mathrm{wt}}$ and each of the mutants at an MOI of 0.3. The cells were incubated in DMEM at $37{ }^{\circ} \mathrm{C}, 5 \% \mathrm{CO}_{2}$ for up to $48 \mathrm{~h}$. At each time point the cultures were harvested by media removal, the addition $200 \mu \mathrm{L} \mathrm{SPG}$, and storage at $-80{ }^{\circ} \mathrm{C}$. The plates were thawed and the McCoy B cells lysed by pipette disruption and cell lysates for each time point were serially diluted and used to re-infect fresh McCoy B cell monolayers in DMEM $+1 \mu \mathrm{g} / \mathrm{mL}$ cycloheximide on 96-well plates, in triplicate. The infectious yield was determined as described above.

\section{Morphological analysis and immunocytochemistry}

Chlamydia cultures were visualised with immunofluorescence as previously described [16, 27]. Briefly, confluent McCoy B cells seeded on $8 \mathrm{~mm}$ coverslips in a 48-well plate were infected with Chlamydia at an MOI of 0.3 in DMEM media and were stained with the Chlamydia Cel LPS product (Cellabs, Brookvale, NSW, Australia) as per the manufacturer's instructions. Primary antibody was incubated for $1 \mathrm{~h}$ in $1 \%$ BSA followed by two washes in PBS. Secondary antibodies were Alexa Fluor 488 goat antirabbit (Life Technologies, USA) and were used at 1/600 
dilution in $1 \%$ BSA for $1 \mathrm{~h}$. Coverslips were mounted using Prolong Gold antifade (Life Technologies, USA) and viewed under a Leica TCS SP5 confocal laser scanning microscope (Leica Microsystems). Images were captured using the Leica application suite for advanced fluorescence.

\section{Genetic analysis of C. trachomatis strains with EMS generated mutations}

$C t \mathrm{~L} 2_{\mathrm{wt}}$ and mutants were semi-purified and genomic DNA was extracted using the phenol-chloroform method as previously described [28]. Whole genome sequencing was performed commercially by the Micromon sequencing facility on the Illumina MiSeq platform, using theTruSeq v3 chemistry and the NexteraXT Library Preparation Kit (Monash University, Victoria, Australia). SNV analysis was performed using Nesoni (https://github.com/Victorian-BioinformaticsConsortium/nesoni) with the $C$. trachomatis L2 434/Bu complete genome (RefSeq accession: NC_010287) serving as the reference sequence.

\section{Lateral gene transfer}

Spectinomycin-resistant $\left(\mathrm{Spc}^{\mathrm{R}}\right)$ C. trachomatis $\mathrm{L} 2$ isolates and rifampicin-resistant $\left(\operatorname{Rif}^{\mathrm{R}}\right)$ mutant isolates were generated by repeated passage on McCoy B cells in the presence of sub-inhibitory concentrations of the antibiotic. Passaging continued until maximum resistance was reached in the presence of $200 \mathrm{ng} / \mathrm{mL}$ rifampicin or $200 \mu \mathrm{g} / \mathrm{mL}$ spectinomycin. Lateral gene transfer between the $\mathrm{Spc}^{\mathrm{R}} C t \mathrm{~L} 2_{\mathrm{wt}}$ and $\mathrm{Rif}^{\mathrm{R}}$ mutant was induced by co-infecting each strain at an MOI of 4.0 in 12 wells of a 24-well plate (total MOI of 8.0). Positive controls were included by infecting duplicate wells in the presence of rifampicin only or spectinomycin only. Negative control wells with no antibiotics were also included. The cell lysates from each well were serially diluted and used to infect a fresh McCoy $B$ cell monolayer on 6-well plates for plaque purification cultures [21].

\section{Results}

Chemical mutagenesis allows identification of SNVs that impact on $\mathrm{CtH}$ trA function

Two existing libraries of $C$. trachomatis mutants were screened for mutations in the cthtrA gene, one based on C. trachomatis serovar L2 (CTL0195) and the other on C. trachomatis serovar D (CT_823). The screening of two libraries was performed to enable enable higher coverage of the cthtrA gene, while enabling the reduction of possible SNV bias given that the libraries were prepared using different methods. The C. trachomatis L2 and D serovars share $99.5 \%$ nucleotide identity and 99.4\% amino acid identity at the cthtrA locus and thus are not expected to exhibit functional differences.
Firstly, we determined that there were $797 \mathrm{C} / \mathrm{G}$ to T/A mutations possible in cthtrA; 601 would be nonsynonymous, 160 synonymous, and 36 nonsense. We have previously used a chemical inhibition approach to demonstrate that $C t \mathrm{HtrA}$ is critical for the survival of C. trachomatis [15], so it was expected that strains harboring null mutations in cthtrA would be nonviable. However, strains containing cthtrA alleles with non-synonymous mutations in functionally important residues could potentially be used to investigate CtHtrA physiological function(s). The first library screened was a collection of 937 C. trachomatis serovar L2 (434/Bu) mutant strains in which each SNV was mapped by whole genome sequencing. This library was generated with a mutation frequency ranging from 6 to 25 mutations per genome following treatment with EMS and ENU [29]. The second library screened was based on C. trachomatis serovar D-LC (CtD-LC) [30] and included 4600 mutant strains with a mutation frequency of seven SNVs per genome. Between the two libraries a total of 5537 mutants were screened and a total of 52 cthtrA variants were identified (Additional file 1: Table S1). Eighteen variants had synonymous substitutions and were excluded from further analysis, while the remaining 35 were analyzed in silico to predict their functional impact based on our previous in silico and biochemical understanding of the CtHtrA amino acid sequence and associated functions $[11,12]$.

\section{Three CtHtrA mutations have an impact on in vitro proteolysis but not oligomerization}

The cthtrA EMS mutations were examined using molecular models of the inactive hexamer and active 24-mer oligomers of CtHtrA, according to $2 \mathrm{D}$ and $3 \mathrm{D}$ structural motifs known to have a role in $C t$ HtrA protein function $[11,12,17,18]$. Mutations were identified throughout the entire cthtrA gene, with SNVs identified in the signal peptide, protease domain, PDZ1 domain, and PDZ2 domain (Additional file 1: Table S1). Six mutations that resulted in amino acid substitutions were selected for characterization based on in silico prediction of a structural and/or functional impact: E47K (G - A), R55Q (G - A), A240V (C - T), G268R (G - A), P370L (C - T), and G475E (G - A) (Fig. 1a). The E47K and R55Q mutations were located at the $\mathrm{N}$-terminus of the protease domain, upstream from loop LA, and had the potential to disrupt the trimeric protease domain interface by forming a steric clash with an adjacent protease domain loop (Fig. 1b). A240V represented a minor substitution from alanine to valine, two small and hydrophobic amino acids, however this residue is situated on loop L1 near to the catalytic serine and any conformational shift that may occur as a result of this mutation, however minor, would likely impact $C t$ HtrA proteolytic activity (Fig. 1b). G268R was situated in the protease domain active site in loop L2 


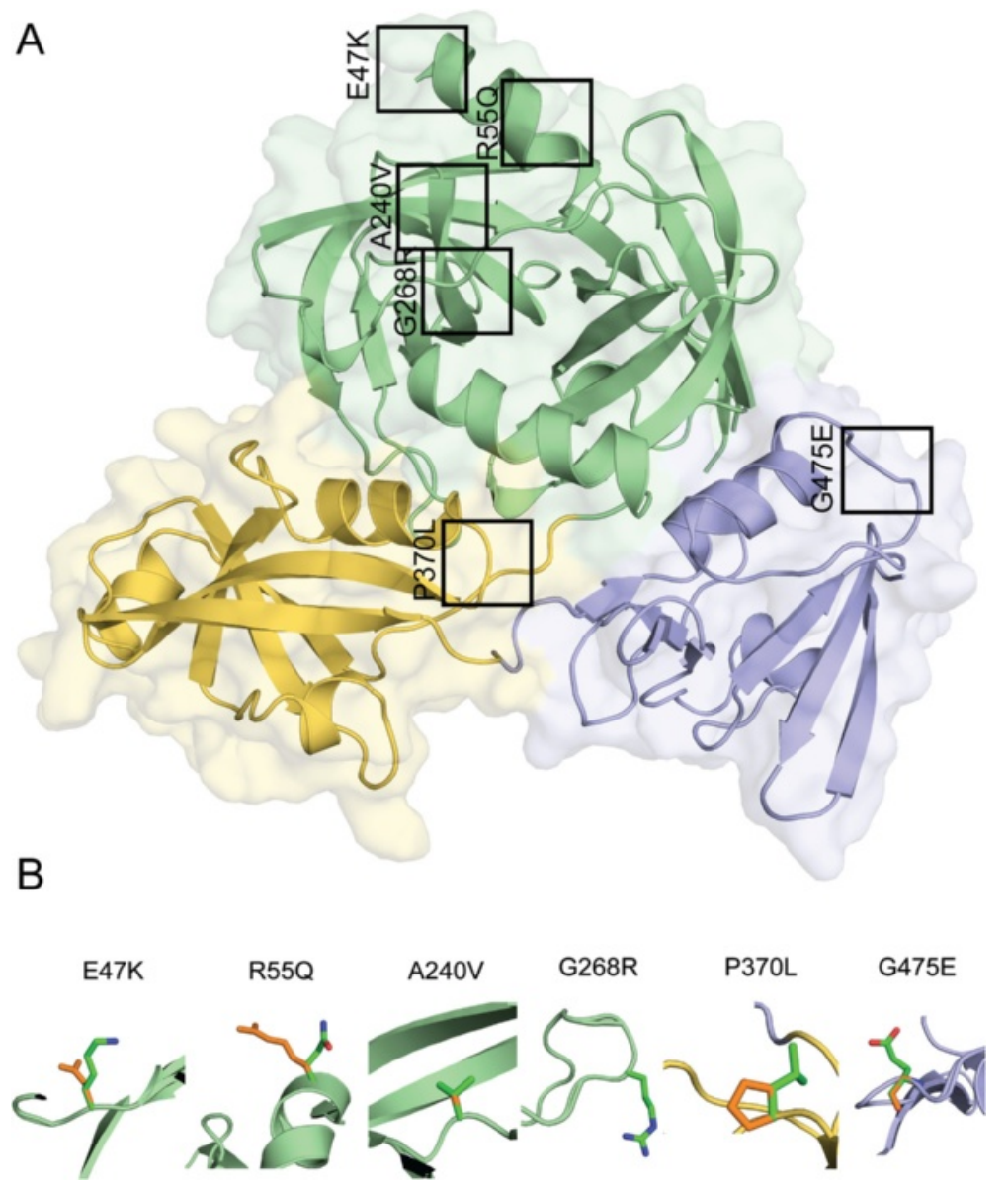

Fig. 1 Mutated residues shown on the CtHtrA monomer of the active 24-meric structure. $\mathbf{a}$. The CtHtrA active monomer with black boxes indicating the location of mutated residues. Green: protease domain, orange: PDZ1 domain, blue: PDZ2 domain. b. Close-up of wild-type residues (orange side-chain) aligned with the mutated residue (green side-chain)

and potentially results in a steric clash with loop L2 from an adjacent protease domain, also potentially disrupting proteolysis (Fig. 1b). P370L was located in the PDZ1 domain at the base of the 'carboxylate binding loop' and is likely to disrupt the conformational turn of this loop, which may impact the binding of the substrate $\mathrm{C}$-terminus to the PDZ1 domain and the subsequent activation cascade (Fig. 1b). G475E was located in the PDZ2 domain and resulted in a potential steric clash with a nearby PDZ2 domain loop, as well as an adjacent PDZ1 domain in the oligomeric state, thus potentially affecting the oligomerization mechanism (Fig. 1b). These six mutations were then generated in vitro in our $\mathrm{Ct} \mathrm{HtrA}$ recombinant protein expression construct using site-directed mutagenesis for biochemical characterization of the recombinant mutated proteins.

The proteolysis and oligomerization activities of these recombinant proteins were compared to the wild-type recombinant protein $(\mathrm{CtHtrA})$. All recombinant proteins were able to cleave full-length $\beta$-casein at $37{ }^{\circ} \mathrm{C}$, with proteins $C t \mathrm{HtrA}_{\mathrm{E} 47 \mathrm{~K}}, C t \mathrm{H}_{\operatorname{trA}} \mathrm{A}_{\mathrm{G} 268 \mathrm{R}}$, and $C t \mathrm{Htr} \mathrm{A}_{\mathrm{R} 55 \mathrm{Q}}$ displaying similar proteolytic activity to the wild-type (Fig. 2a). The rate of proteolysis was slower for the $C t \mathrm{HtrA}_{\mathrm{A} 240 \mathrm{~V}}$, and $C t \mathrm{HtrA}_{\mathrm{G} 475 \mathrm{E}}$ proteins compared to the wild type, while the proteolysis activity of the $C t \mathrm{Htr} \mathrm{A}_{\mathrm{P} 370 \mathrm{~L}}$ was substantially reduced (Fig. 2a; Additional file 2: Figure S1). Similarly, in the presence of a peptide substrate, the $C t \mathrm{HtrA}_{\mathrm{A} 240 \mathrm{~V}}$ and $\mathrm{Ct} \mathrm{HtrA}_{\mathrm{G} 475 \mathrm{E}}$ proteins demonstrated a reduction in proteolytic rate, respectively, compared to the wild-type, while no proteolytic activity could be detected for the CtHtrA $\mathrm{A}_{\mathrm{P} 30 \mathrm{~L}}$ protein (Fig. 2b). The proteolytic rate of the $C t \mathrm{HtrA}_{\mathrm{G} 268 \mathrm{R}}$ and $C t \mathrm{HtrA}_{\mathrm{R} 55 \mathrm{Q}}$ proteins were not substantially different from the wild-type. We have previously shown that the addition of a second peptide based on the $12 \mathrm{C}$-terminal residues of $\beta$-casein (Act1) can activate or increase the proteolytic activity of $C t \mathrm{HtrA}[11,12]$. Thus, the activation of proteolysis by the recombinant proteins was investigated and a 1.4-2.3-fold increase in the rate of proteolysis was observed for $C t \mathrm{H}_{\operatorname{trA}} \mathrm{E}_{\mathrm{E} 7 \mathrm{~K}}, C t \mathrm{H}_{\operatorname{trA}} \mathrm{A}_{\mathrm{G} 268 \mathrm{R}}, C t \mathrm{HtrA}_{\mathrm{R} 55 \mathrm{Q}}, C t \mathrm{HtrA}_{\mathrm{A} 240 \mathrm{~V}}$ and $C t \mathrm{HtrA}_{\mathrm{G} 475 \mathrm{E}}$. Alternatively, $C t \mathrm{H}_{\operatorname{trA}} \mathrm{A}_{\mathrm{P} 370 \mathrm{~L}}$ displayed no 


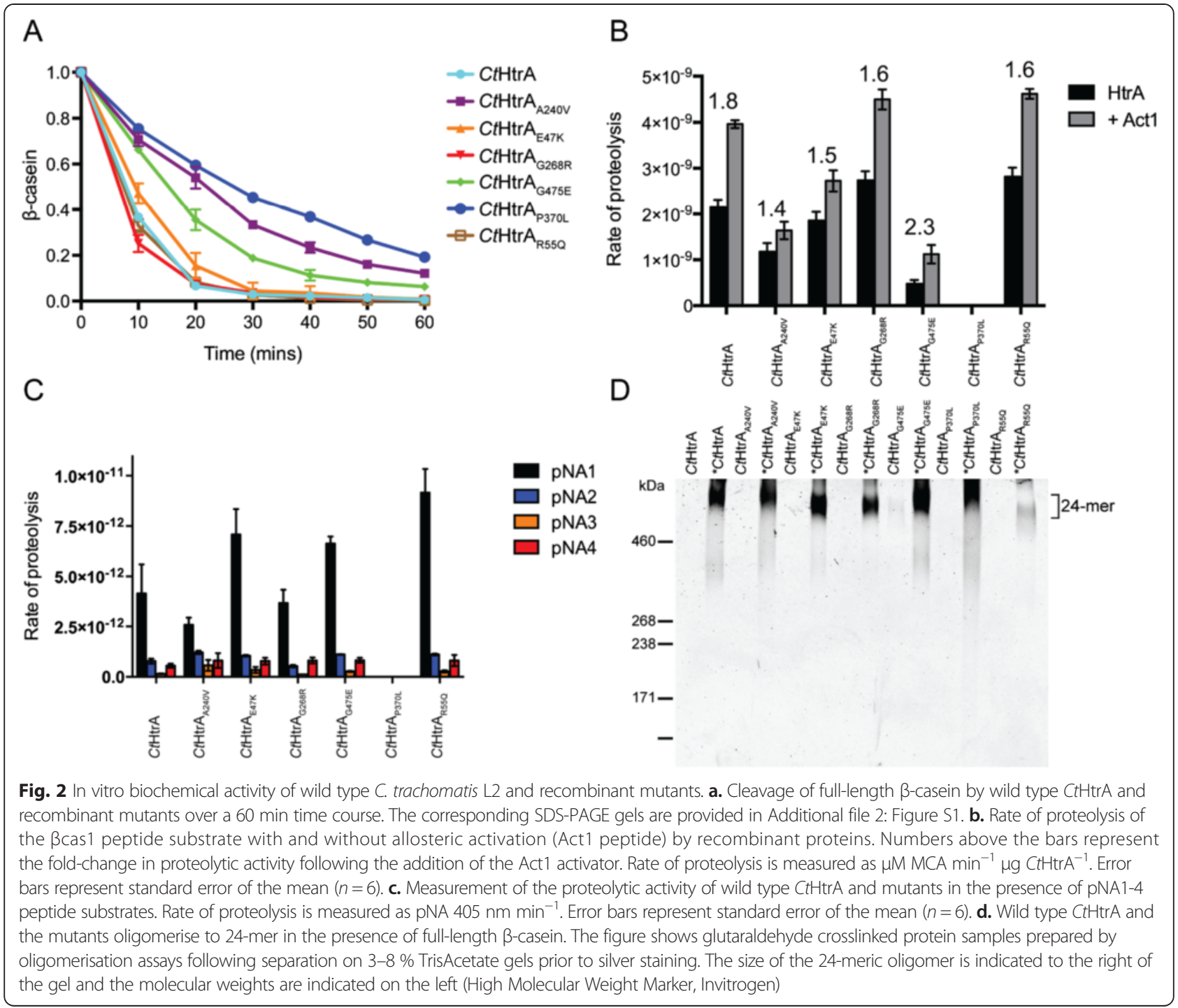

detectable proteolytic activity against this peptide substrate (Fig. 2b), which may be due to this mutation causing a conformational change to the 'PDZ1 activation cleft', impacting the correct binding of Act1. Substrate specificity of the proteins was also examined using different para-Nitroanilide (pNA)-labeled substrates that differ in length and sequence (P1 - P4). No differences in substrate specificity were observed for any of the proteins compared to the wild type, suggesting that the mutations do not appreciably change the conformation of the catalytic domain (at least using these substrates; Fig. 2c). The $C t \mathrm{HtrA}_{\mathrm{P} 370 \mathrm{~L}}$ protein again displayed no proteolytic activity. $C t \mathrm{HtrA}$ has been previously shown to oligomerize from a resting hexamer to an activated 12-/24-mer in the presence of both peptide and protein substrates $[11,12]$. To investigate whether any of the recombinant mutated protein disrupted or impaired the activation of oligomerization, each were incubated with full-length $\beta$-casein at $37{ }^{\circ} \mathrm{C}$ and crosslinked with glutaraldehyde. In the presence of substrate, each mutant formed particles that are consistent with a higher order oligomer of CtHtrA (such as a 24-mer), with no evidence of the hexameric or trimeric forms that are observed when the oligomerization mechanism has been disrupted [12,31]. While this method cannot detect differences in oligomeric structure or the exact number of monomers present, oligomeric activation to some form of oligomer appears to be unperturbed for each of the mutants (Fig. 2d) [11]. These data demonstrated that the $C t \mathrm{H}_{\operatorname{tr}} \mathrm{A}_{\mathrm{A} 240 \mathrm{~V}}, C t \mathrm{H}_{\operatorname{trA}} \mathrm{A}_{\mathrm{G} 475 \mathrm{E}}$, and $C t \mathrm{H}_{\text {trA }} \mathrm{P}_{370 \mathrm{~L}}$ mutations resulted in an appreciable disruption to the in vitro proteolytic activity of $C t \mathrm{HtrA}$ and therefore isolates with these three mutations were selected from the libraries for further in vitro analysis of their phenotypic impact on chlamydial growth. 


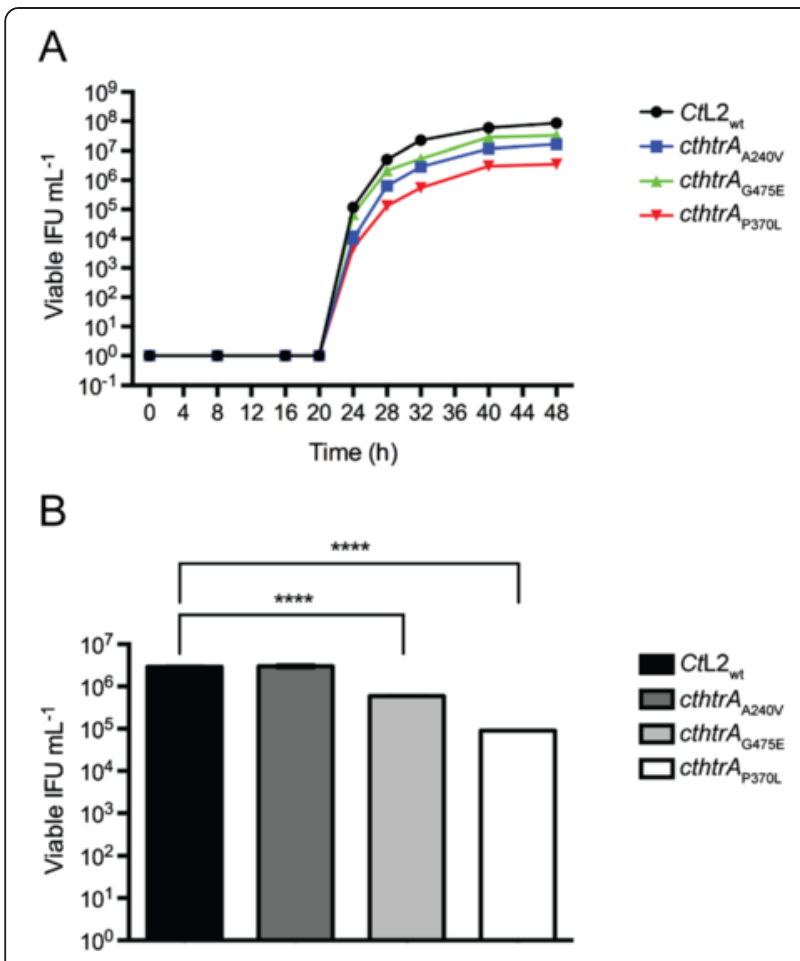

Fig. 3 Growth and heat shock response phenotypes for C. trachomatis mutants containing cthtrA SNVs. a. One-step growth curve for $C t L 2_{w t}$ and mutants over a $48 \mathrm{~h}$ time course. McCoy B cells were infected at an $\mathrm{MOl}$ of 0.3 and collected over the time course for determination of inclusion-forming units (IFUs). b. Infectious yield of $\mathrm{CtL} 2_{\text {wt }}$ and mutants at $44 \mathrm{~h}$ post infection after $4 \mathrm{~h}$ heat shock $\left(42{ }^{\circ} \mathrm{C}, 5 \% \mathrm{CO}_{2} ; 20-24 \mathrm{~h}\right.$ post infection). ${ }^{* * *}$ indicates $p<0.0001$. Error bars represent standard error of the mean $(n=27)$

\section{A strain with a P370L substitution in cthtrA exhibits} decreased or delayed EB production

Previous work by our group suggested that $C t \mathrm{HtrA}$ has a crucial role in the replicative phase of $C$. trachomatis development, as the JO146 CtHtrA inhibitor was lethal when added to the cultures at mid-replication [15]. Accordingly, growth rates were assessed for Chlamydia strains containing the $c$ thtr $A$ variants $c$ thtr $A_{\mathrm{A} 240 \mathrm{v}}, c t h t r A_{\mathrm{P} 370 \mathrm{~L}}, c t h t r A_{\mathrm{G} 475 \mathrm{E}}$ and wild-type $C$. trachomatis serovar L2 (referred to as for this study $C t \mathrm{~L} 2_{\mathrm{wt}}$ ) (Additional file 1 : Table S2), by determining the time at which infectious EBs were first detected, with additional times points during the growth cycle. The presence of infectious EBs was detected between 20 and $48 \mathrm{~h}$ post-infection, with each mutant strain producing fewer EBs than the wild-type (Fig. 3a). The $\operatorname{cth}$ tr $A_{\mathrm{P} 370 \mathrm{~L}}$ mutant produced significantly fewer infectious EBs compared to the wild type and other mutants, displaying a $\sim 20-40$-fold reduction ( $~ 95 \%$ reduction) in infectious EB progeny (for example at $32 \mathrm{~h}$ post infection, $2.26 \times 10^{7}$ EBs were detected for $C t \mathrm{~L} 2$ wt while $5.45 \times 10^{5}$ EBs were detected for $\operatorname{cthtr} A_{\mathrm{P} 370 \mathrm{~L}}$, corresponding to a 41.4-fold reduction in infectious EB production at this time point).
The C. trachomatis isolate harboring a P370L substitution in cthtrA displays increased susceptibility to heat shock

The role of bacterial HtrA during heat shock has been widely reported [32-34], and CtHtrA in particular has been shown to be upregulated during heat stress conditions [16] and critical for heat stress survival when the chemical inhibitor against CtHtrA was used [14]. Therefore, Chlamydia strains with functionally disruptive mutations in cthtrA are likely to be more severely impacted by heat stress. HEp-2 cells were infected with each strain and subjected to $42{ }^{\circ} \mathrm{C}$ heat shock during the replicative phase $(20 \mathrm{~h}$ post-infection) for $4 \mathrm{~h}$, prior to restoration to $37{ }^{\circ} \mathrm{C}$ for the remainder of the development cycle. The impact of heat shock treatment on the mutants was determined by calculating the subsequent infectious yield from cultures harvested at $44 \mathrm{~h}$ post infection. The $c$ thtr $A_{\mathrm{A} 240 \mathrm{~V}}$ mutant had an infectious yield that was comparable to the wild-type, while both the $c t h t r A_{\mathrm{G} 475 \mathrm{E}}$ and $c \operatorname{thtr} A_{\mathrm{P} 370 \mathrm{~L}}$ mutants exhibited a significant reduction in infectious yield following heat shock, relative to the wild-type (Fig. 3). Notably, the cthtr $A_{\mathrm{P} 370 \mathrm{~L}}$ mutant resulted in a 32.5 -fold reduction in infectious EB yield following heat shock compared to the wild type $(p<0.0001)$.

\section{The cthtr $A_{\mathrm{P} 370 \mathrm{~L}}$ inclusions are smaller in size}

The impact of the mutations on the chlamydial inclusion morphology was examined using immunocytochemistry and confocal laser scanning microscopy. Cultures were examined at $24 \mathrm{~h}$ post-infection (log phase) and $40 \mathrm{~h}$ postinfection (stationary phase; Fig. 4). At $24 \mathrm{~h}$ post-infection, the inclusion size of each mutant appeared smaller compared to the wild-type, while in the $\operatorname{cth} t r A_{\mathrm{P} 370 \mathrm{~L}}$ strain there appeared to be fewer chlamydial cells within the inclusions. At $40 \mathrm{~h}$ post-infection, the inclusion sizes appeared to be more comparable to the wild-type, if slightly smaller. The inclusion sizes were measured to allow statistical comparison of the mutants against the wild-type, confirming that the mutant inclusion sizes were appreciably smaller compared to the wild-type at $24 \mathrm{~h}$ post-infection (Fig. 5). The difference was less pronounced at $40 \mathrm{~h}$ post-infection, where the $c t h t r A_{\mathrm{G} 475 \mathrm{E}}$ inclusion sizes were not significantly different compared to the wild-type. Alternatively, in the $\operatorname{cthtr} A_{\mathrm{A} 240 \mathrm{~V}}$ and, to a greater extent, $\operatorname{cth} \operatorname{tr} A_{\mathrm{P} 370 \mathrm{~L}}$ strains, inclusion sizes were significantly smaller than the wild-type $(p<0.0001$; Fig. 5).

Genomics and lateral gene transfer to isolate chlamydial SNVs for further characterization resulted in a ct|0738 but not a cthtrA $A_{P 370 L}$ isogenic strain

While these observed phenotypes are consistent with our previous observations for CtHtrA function, it is likely that the additional SNVs present in these mutant genomes also contribute to the phenotype. As a result, 


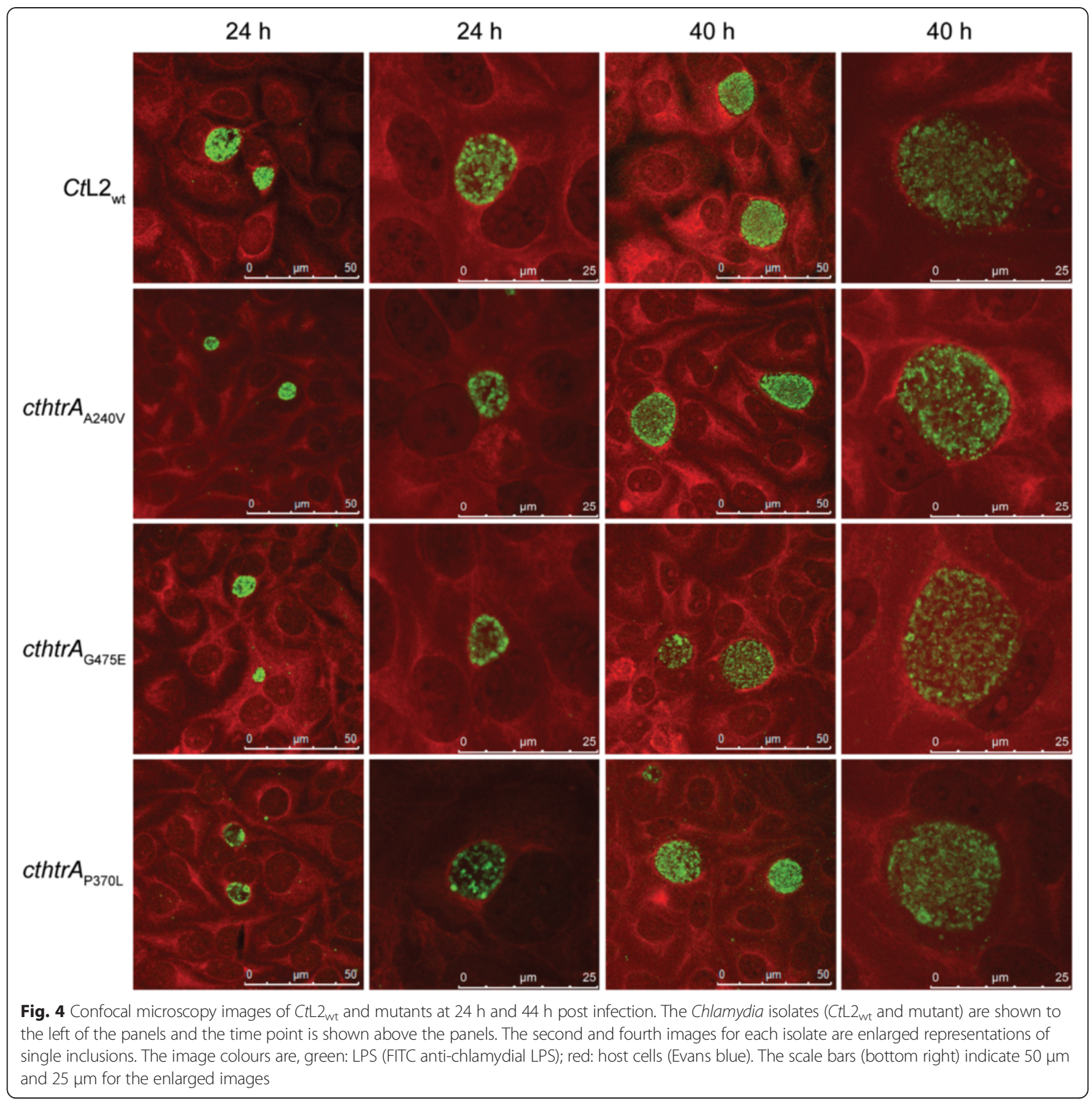

the genome sequences of the $c$ thtr $A_{\mathrm{A} 240 \mathrm{~V}}, \operatorname{cth} t r A_{\mathrm{G} 475 \mathrm{E}}$, and $c t h t r A_{\mathrm{P} 370 \mathrm{~L}}$ mutants were determined by whole genome sequencing (WGS). When compared to the $C t \mathrm{~L} 2_{\mathrm{wt}}$ genome sequence, the mutants consisted SNVs at nine loci that were consistent in all three isolates $\left(c t h t r A_{\mathrm{A} 240 \mathrm{~V}}\right.$, cthtr $A_{\mathrm{G} 475 \mathrm{E}}$, and cthtr $\left.A_{\mathrm{P} 370 \mathrm{~L}}\right): \operatorname{ctl0103,~nusA,ctl0518,clpC-}$ 1, $\operatorname{clpC}-2, r p o B, p y k F$, and $p m p C$, which were confirmed to originate from the $C t \mathrm{~L} 2_{\text {rif }}$ strain used to generate the library (Additional file 1: Table S2) and were thus not expected to contribute to the observed phenotypes. Alternatively, we observed 13 unique SNVs in the $\operatorname{cth} t r A_{\mathrm{A} 240 \mathrm{~V}}$ (including the A240V C - T transition at position 247526 in $\operatorname{cthtrA}$ ), 19 unique SNVs in the $\operatorname{cthtr} A_{\mathrm{P} 370 \mathrm{~L}}$ isolate (including the P370L C - T transition at position 247916 in cthtr $A$ ), and eight unique SNVs in the $\operatorname{cth} t r A_{\mathrm{G} 475 \mathrm{E}}$ isolate (including the G475E G - A transition at position 248231 in $\operatorname{cthtrA}$; Additional file 1: Table S3), which could potentially contribute to the observed phenotypes.

Given that the isolate with the $c t h t r A_{\mathrm{P} 370 \mathrm{~L}}$ mutation displayed the most marked phenotypes and was severely impaired during $C t \mathrm{HtrA}$ recombinant protein in vitro protease assays, it was reasoned that this isolate will be the most informative for determining the physiological function of CtHtrA and was selected for further genetic 


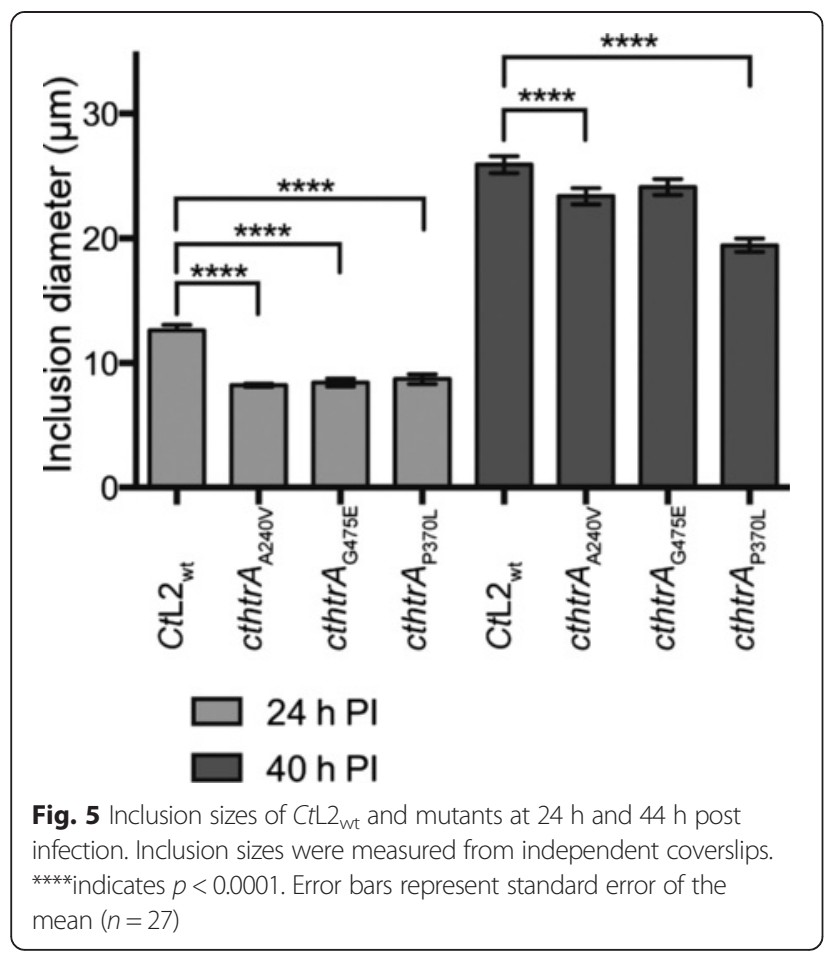

characterization. Of the 19 unique SNVs in the genome of the $\operatorname{cth} \operatorname{tr} A_{\mathrm{P} 370 \mathrm{~L}}$ mutant isolate, 11 were non-synonymous, five were synonymous, and three were located in intergenic regions. Notably, there was a null mutation in ctlo738, a putative DNA methyltransferase. Of the eleven nonsynonymous mutations, three resulted in a change to a similar amino acid (i.e. polar, hydrophobic etc.) and are therefore unlikely to have a functional effect (these were SNVs found in ctl0493, metG, and ctl0220). Consequently, a total of eight SNVs in the following $c$ thtr $A_{\mathrm{P} 370 \mathrm{~L}}$ isolate were identified as potentially significant, found on the following locus: $r e c \mathrm{~B}, m u r \mathrm{C}$, inc $\mathrm{A}, y d h \mathrm{O}, c t l 0738$ (putative DNA methyltransferase), ctl0791 (putative membrane protein), ctl0885 (conserved hypothetical protein), and cthtr $A_{\mathrm{P} 370 \mathrm{~L}}$ (Fig. 6, Additional file 1: Table S3).

In an effort to separate the cthtrA $A_{\mathrm{P} 370 \mathrm{~L}} \mathrm{SNV}$ from these remaining SNVs, a lateral gene transfer approach was utilized, by co-infecting host cells with the rifampicin resistant $c_{\text {thtr }} A_{\mathrm{P} 370 \mathrm{~L}}$ stain and a spectinomycin resistant $C t \mathrm{~L} 2_{\mathrm{wt}}$ strain to generate recombinant isolates [21]. Positive recombinants were selected by plaque purification in the presence of both antibiotics. PCR and Sanger sequencing was conducted on 56 plaque-purified double resistant recombinant strains for the cthtr $A_{\mathrm{P} 370 \mathrm{~L}} \mathrm{SNV}$ and ctl738 $8_{\text {null }}$ (DNA methyltransferase), in addition to the other SNVs identified as potentially significant. The $c t h t r A_{\mathrm{P} 370 \mathrm{~L}}$ SNV was not detected in any of the 56 plaque purified recombinant isolates, while the $c t l 0738_{\text {null }} \mathrm{SNV}$ was variously distributed among the recombinants. One recombinant isolate $\left(c t l 0738_{\text {null }}\right)$ contained the ctl0738 SNV and none of the other seven SNVs, allowing the potential for characterization of the DNA methyltransferase null mutation in the absence of the cthtrA $A_{\mathrm{P} 370 \mathrm{~L}}$ and remaining SNVs.

Characterization of the ct|0738 null mutation suggests that the cthtrA $A_{P 370 L} S N V$ is the major contributor to the reduced infectious progeny phenotype

The lateral gene transfer experiments did not enable the generation of an isogenic cthtrA $A_{\mathrm{P} 370 \mathrm{~L}}$ mutant isolate. The SNV that could be contributing to the phenotype observed in the $c t h t r A_{\mathrm{P} 370 \mathrm{~L}}$ strain was the null mutation in the DNA methyltransferase, $c t l 0738$. This mutation was able to be transferred to the genome of $C$. trachomatis $\mathrm{L} 2$ spectinomycin-resistant strain $\left(C t \mathrm{~L} 2_{\mathrm{spc}}\right)$ in the absence of the eight other EMS mutations that were considered potentially significant on the $c_{t H} \operatorname{tr}_{\mathrm{P} 370 \mathrm{~L}}$ isolate genome. Therefore, further analysis of the isogenic strain containing the DNA methyltransferase null $\left(\right.$ ctlO $\left.738_{\text {null }}\right)$ was conducted to examine the role of this mutation for the phenotypes observed in the cthtrA $A_{\mathrm{P} 370 \mathrm{~L}}$ strain. Growth curve and heat shock experiments were conducted using the wild type strains $\left(C t \mathrm{~L} 2_{\mathrm{wt}}\right.$ and $\left.C t \mathrm{~L} 2_{\mathrm{spc}}\right)$, the original cthtr $A_{\mathrm{P} 370 \mathrm{~L}}$ mutant strain, and the $c t l 0738_{\text {null }}$ strain. The $c t h t r A_{\text {P370L }}$ strain has the same severely impacted reduced infectious progeny yield (8-25-fold reduction in infectious progeny; Fig. 7a) and the $c t l 0738_{\text {null }}$ strain showed infectious progeny production similar to the wild type. Notably, by including additional time-points at the beginning of the replicative phase (16-22 $\mathrm{h}$ post infection), it was observed that both the cthtr $A_{\mathrm{P} 370 \mathrm{~L}}$ and $c t l 0738_{\text {null }}$ strains displayed a delayed start to the log growth phase implying slowed RB to EB conversion. Somewhat unexpectedly, the heat stress phenotype was similar in the cthtrA $A_{\mathrm{P} 370 \mathrm{~L}}$ and $c t l 0738_{\text {null }}$ strains with a significant reduction in infectious progeny $\left(C t \mathrm{~L} 2_{\mathrm{wt}}: 4.5 \times 10^{7}\right.$ EBs, $c$ thtr $A_{\mathrm{P} 370 \mathrm{~L}}: 1.2 \times 10^{6} \mathrm{EBs} ;$ ctlo738 $8_{\text {null }}: 1.4 \times 10^{6}$ EBs; $p<0.0001$ ), corresponding with a $30-40$-fold reduction in infectious progeny after heat stress relative to $C t \mathrm{~L} 2_{\mathrm{wt}}$ (Fig. $7 \mathrm{~b}$ ).

\section{Discussion}

Here we present genetic evidence that cthtrA has a role in the production of infectious EBs. There are a number of possible conclusions that could be hypothesized based on the results presented here. Firstly, we did not find cthtrA alleles with null mutations in either library, so it is tempting to speculate that such a mutation would not be viable, however, considerably greater numbers of mutant strains would need to be screened before we could conclude with confidence that null mutations in cthtrA are not permissible. Although, we have previously demonstrated that a $C t \mathrm{HtrA}$ specific chemical inhibitor of its protease activity is completely lethal when added during 


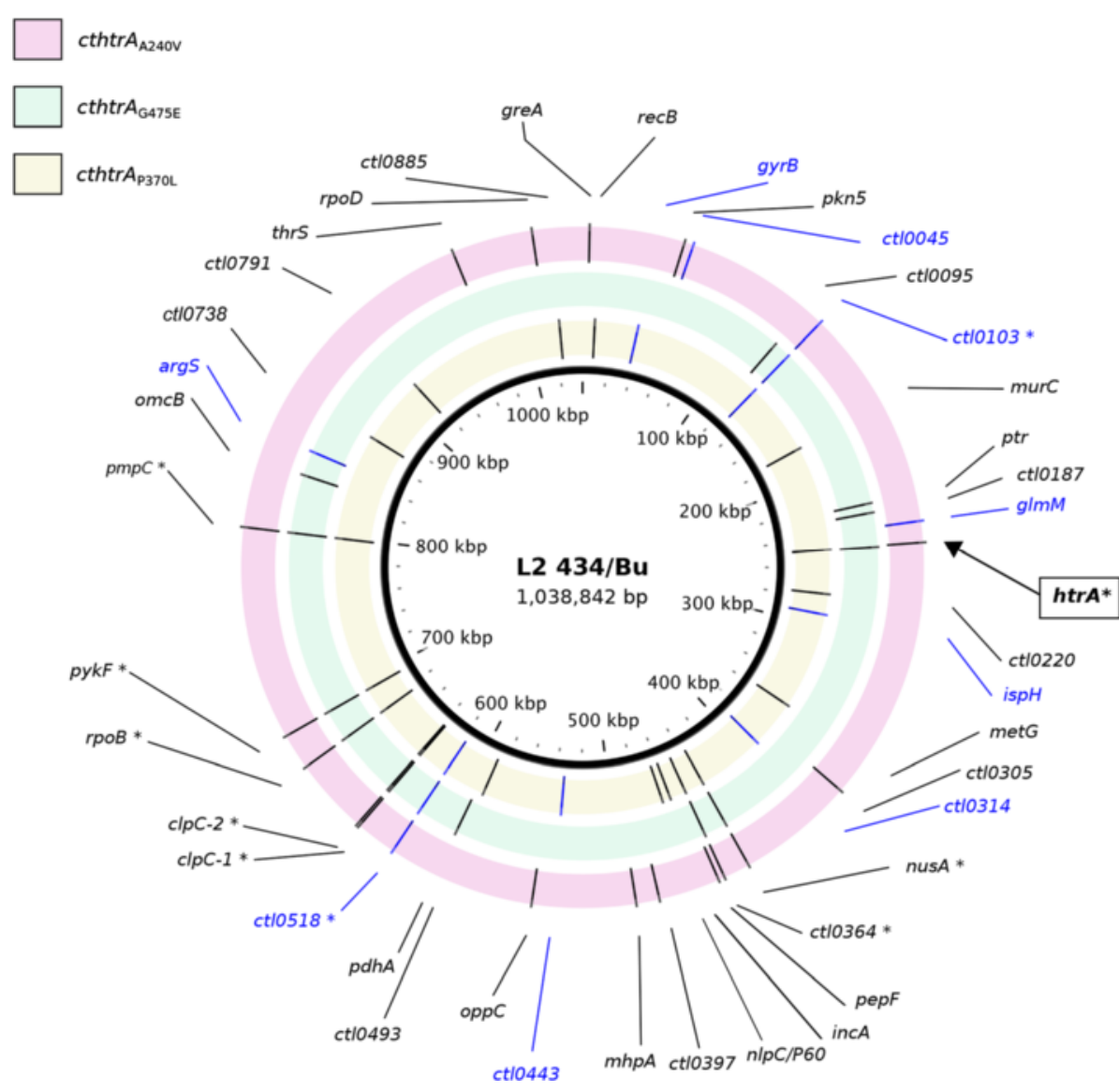

Fig. 6 Circular representation of the reference L2/434/Bu genome (1.04 Mbp) showing the position of SNVs found on protein coding genes and

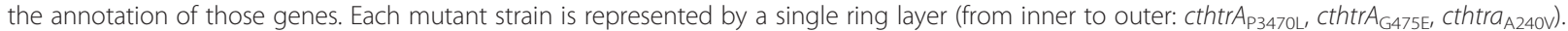
Blue labels correspond to synonymous SNVs and black labels indicate non-synonymous SNVs. Figure generated using BRIG [37]

the replicative phase of the developmental cycle [15], which supports that it may not be possible to isolate strains with null mutation in cthtrA.

We were able to identify a strain with a SNV resulting in an amino acid substitution (P370L) in the cthtrA sequence, that resulted in a severe reduction in proteolytic activity in the recombinant protein bearing the substitution. However, we expect there is some proteolytic activity by this form of $C t$ HtrA (cthtrA $\left.A_{\mathrm{P} 370 \mathrm{~L}}\right)$ in vivo. Firstly, our in vitro assays are based on model substrates requiring a second peptide for allosteric activation of maximal protease activity and thus may not accurately reflect in vivo activity. Secondly, the assay against the full-length $\beta$-casein protein demonstrated in vitro protease activity for this mutated protein, suggesting that in vivo activity is likely to be present. Given that the strain is still viable and that chemical inhibition of the proteolysis activity of CtHtrA was found to be lethal [15], we suspect some $C t$ HtrA proteolysis activity is occurring in vivo in this strain $\left(c t h t r A_{\mathrm{P} 370 \mathrm{~L}}\right)$. While causality will require additional genetic evidence, this mutation to be a major contributor to the severe defect in the production of infectious EBs we observed in the cthtrA $A_{\mathrm{P} 370 \mathrm{~L}}$ mutant strain (20-40-fold reduction), that was not contributed to by the ctl0738 SNV (as this was not observed in the

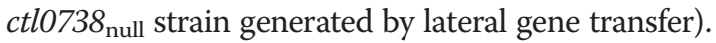

The $c$ thtr $A_{\mathrm{P} 370 \mathrm{~L}}$ strain had 18 SNVS compared to 11 and 8 SNVs detected in the cthtrA $A_{\mathrm{A} 240 \mathrm{~V}}$, cthtr $_{\mathrm{G} 475 \mathrm{E}}$ strains respectively, and hence, while it is tempting to attribute the phenotypes observed to the P370L mutation, it could in fact be a consequence of a combination of mutations or one of the other mutations alone. However, we can be confident that the reduced infectious EB production phenotype is not a consequence of the $c t l 0738_{\text {null }} \mathrm{mu}-$ tation, based on the data in Fig. 7a. It was surprising to observe that the $c t 10738_{\text {null }}$ strain showed similar reduced infectious EB yield after heat stress as the $c \operatorname{thtr} A_{\mathrm{P} 370 \mathrm{~L}}$ isolate, as this model of stress is not expected to induce DNA damage that would require the repair enzyme predicted to be encoded by this locus [35].

Perhaps the most important result is that after lateral gene transfer experiments and the screening of 56 plaque purified isolates, no strain was identified containing the P370L mutation ( $\mathrm{C}-\mathrm{T}$ at nucleotide position 247916). This could be random chance or could suggest that the 

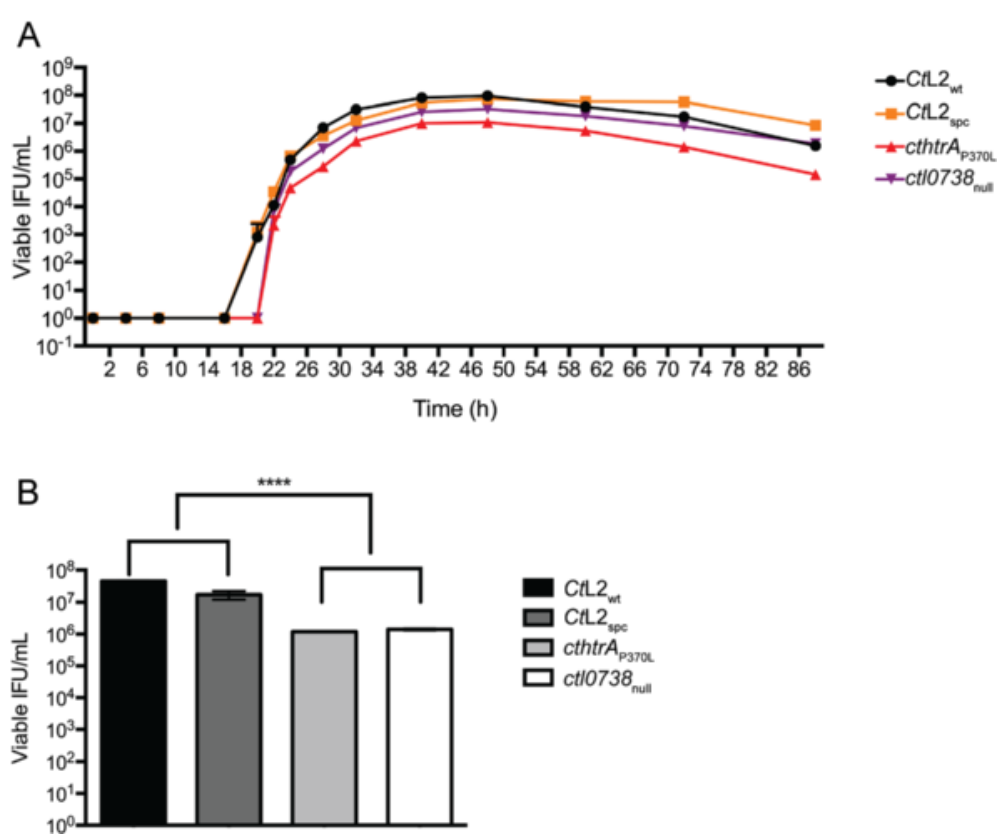

Fig. 7 Cell culture analysis of growth and heat shock phenotypes for the cthtrAp370L and ct/0738null mutants. a. One-step growth curve for wild-type $C$. trachomatis L2 and mutants over an $88 \mathrm{~h}$ time course. McCoy B cells were infected at an $\mathrm{MOI}$ of 0.3 and collected over the time course for determination of inclusion-forming units. b. Viable infectious yield of wild-type C. trachomatis L2 and mutants at $44 \mathrm{~h}$ post infection after $4 \mathrm{~h}$ heat shock $\left(42^{\circ} \mathrm{C}, 5 \%\right.$ $\mathrm{CO}_{2} ; 20-24 \mathrm{~h}$ post infection). ${ }^{* * * * i n d i c a t e s} p<0.0001$. Error bars represent standard error of the mean $(n-27)$

P370L mutation in isolation is responsible for a severe growth defect that prevented us from isolating any strains during these experiments. Alternatively, it is possible that one of the other SNVs is suppressing the P370L mutation in the $c t h t r A_{\mathrm{P} 370 \mathrm{~L}}$ strain. Given that we expect $C t \mathrm{HtrA}$ 's function to impact the integrity of several chlamydial cell envelope proteins, including major outer membrane protein (MOMP), Porin B (PorB), and the polymorphic membrane proteins (Pmps) [12], CtHtrA's chaperone and protease activity as a stress response and housekeeping protein important for outer membrane protein assembly could be indirectly driving the observed phenotypes [31, 36].

The smaller inclusion sizes observed in the $\operatorname{cth} t r A_{\mathrm{P} 370 \mathrm{~L}}$ strain corresponds with the reduced infectious EB yield suggesting a growth defect (possibly relating to optimal replication) could be a consequence of reduced CtHtrA function, likely indirectly due to the function of a substrate that requires $C t \mathrm{HtrA}$ for correct assembly or maintenance.

Overall, we have provided genetic evidence that $C$. trachomatis with a genetic mutation $(\mathrm{C}-\mathrm{T}$ at position 247916 in $c t h t r A$ ) likely resulted in reduced production of infectious EB, potentially correlating with a negative impact of this mutation on CtHtrA's in vitro proteolytic activity. While genetic causality could not be confirmed, these results provide further evidence that $C t$ HtrA has a critical role during the developmental cycle of Chlamydia.

\section{Conclusions}

HtrA is known to be an important protease for many bacterial pathogens. Analysis of Chlamydia trachomatis genetic mutants possessing variants of the cthtrA gene that firstly showed an impact on proteolytic function by in vitro analysis demonstrated that these mutants had reduced infectious progeny. Thus HtrA has a critical role in formation of chlamydial infectious progeny.

\section{Availability of supporting data}

Supplementary tables are provided. The draft assemblies of all genome sequences generated during this project are available through the EMBL ENA database under the Study number PRJEB9044: http://www.ebi.ac.uk/ena/ data/search?query=PRJEB9044.

\section{Additional files}

Additional file 1: Table S1. EMS library mutants with confirmed non-synonymous SNVs in the cthtrA gene. Table S2. List of bacterial strains used in this study. Table S3. Total SNVs present in the cthtrA $A_{\text {A240V, }}$ cthtrAP370L, and cthtrA $A_{G 45 E}$ mutants as confirmed by whole genome sequencing. Table S4. Sequences and associated annealing temperatures for the PCR primers used in this study. Table S5. Active site substrates and activators used for proteolysis and oligomerisation assays. (DOCX 45 kb)

Additional file 2: Figure S1. SDS-PAGE gels of full length $\beta$-casein cleavage by wild type CtHtrA and mutants over a 60 min time course. A. Wild-type CtHtrA; B. CtHtrA $A_{240 V} ;$ C. CtHtrA E47K; D. CtHtrA $_{\text {G268R; E. CtHtrA }}$ G475E; F. CtHtrA $A_{\text {370L; G. CtHtrA }}$ R55. Lanes are labelled: M: protein molecular weight marker (Bio-Rad); 0 min; 10 min; 20 min; 30 min; 40 min; 50 min; 60 min; H: 
CtHtrA only; $\beta c$ : $\beta$-casein only. The molecular masses of standard proteins are indicated by arrows next to the gels. (DOC $21 \mathrm{~kb}$ )

\section{Abbreviations}

DNP: 2,4-dinitrophenyl; EB: Elementary body; EMS: Ethyl methanesulfonate; FCS: Fetal calf serum; MCA: 7-methoxycoumarin-4-acetic acid; MOMP: Major outer membrane protein; OMP: Outer membrane protein; Pmp: Polymorphic membrane protein; $p N A$ : para-Nitroanilide; RB: Reticulate body;

Rif $^{\text {R: }}$ Reifampicin-resistant; SNV: Single nucleotide variant;

$S_{S p}^{R}$ : Spectinomycin-resistant; TILLING: Targeting induced local lesions in genomes; WGS: Whole genome sequencing.

\section{Competing interests}

The authors declare that they have no competing interests.

\section{Author's contributions}

JM carried out the experimental work and drafted the manuscript. BW conducted the data analysis of the genome sequences and manuscript drafting. JT helped interpret and analyze the data and also contributed to draft the manuscript. BL helped interpret and analyze the data and also contributed to drafting the manuscript. RB screened for and provided the chemical mutants for L2, participated in the data interpretation, and helped draft the manuscript. RV screened for and provided the chemical mutants for either $L 2$, participated in the data interpretation, and helped draft the manuscript. LK screened and provided the chemical mutants for D, participated in the data interpretation, and helped draft the manuscript. HC screened and provided the chemical mutants for $\mathrm{D}$, participated in the data interpretation, and helped draft the manuscript. WH conceived of the study, and participated in its design, participated in data analysis and interpretation and coordination and helped to draft the manuscript. All authors read and approved the final manuscript.

\section{Authors' information}

Not applicable.

\section{Acknowledgements}

Most of the work on Chlamydia HtrA in the Huston group has been supported by NHMRC Project Grant 553020 and an ARC Linkage Project in Conjunction with The Wesley Research Institute. WH has previously received support from an NHMRC Peter Doherty Fellowship. Queensland University of Technology and Institute of Health and Biomedical Innovation funding supported several components of this study. JM wishes to acknowledge the technical and experimental support from Amba Lawrence throughout the experimental work of this study.

\section{Author details}

'Institute of Health and Biomedical Innovation (IHB|), Queensland University of Technology (QUT), 60 Musk Avenue, Kelvin Grove, QLD 4059, Australia. ${ }^{2}$ National School of Pharmacy, University of Otago, PO Box 56, Dunedin 9054, New Zealand. ${ }^{3}$ Department of Molecular Genetics and Microbiology, Center for Microbial Pathogenesis, Duke University Medical Center, Durham, NC 27710, USA. ${ }^{4}$ Laboratory of Intracellular Parasites, National Institute of Allergy and Infectious Diseases, National Institutes of Health, Hamilton, MT 59840, USA.

Received: 18 May 2015 Accepted: 25 September 2015 Published online: 30 September 2015

\section{References}

1. Cartillier LHH. Global Data on Visual Impairments. WHO. 2010;2010:1-17.

2. Rowley J, Toskin I, Ndowa F. Global Incidence and Prevalence of Selected Curable Sexually Transmitted Infections. Sex Reprod Health. 2008;1:1-28.

3. Schachter J. The intracellular life of Chlamydia. Curr Top Microbiol Immunol. 1988:138:109-39.

4. Stephens RS. Genome sequence of an obligate intracellular pathogen of humans: Chlamydia trachomatis. Science. 1998:282:754-9.

5. Lipinska BB, Sharma S, Georgopoulos CC. Sequence analysis and regulation of the htrA gene of Escherichia coli: a $\sigma^{32}$-independent mechanism of heat inducible transcription. Nucleic Acids Res. 1988;16:10053-67.
6. Meltzer M, Hasenbein S, Hauske P, Kucz N, Merdanovic M, Grau S, et al. Allosteric activation of HtrA protease DegP by stress signals during bacterial protein quality control. Angew Chem Int Ed. 2008;47:1332-4.

7. Krojer T, Sawa J, Schäfer E, Saibil HR, Ehrmann M, Clausen T. Structural basis for the regulated protease and chaperone function of DegP. Nature. 2008;453:885-90

8. Wu X, Lei L, Gong S, Chen D, Flores R, Zhong G. The chlamydial periplasmic stress response serine protease $\mathrm{CH}$ trA is secreted into host cell cytosol. BMC Microbiol. 2011;11:87

9. Jones $\mathrm{CH}$, Bolken TC, Jones KF, Zeller GO, Hruby DE. Conserved DegP protease in Gram-positive bacteria is essential for thermal and oxidative tolerance and full virulence in Streptococcus pyogenes. Infect Immun. 2001;69:5538-45.

10. Krojer T, Garrido-Franco M, Huber R, Ehrmann M, Clausen T. Crystal structure of DegP $(H$ trA $)$ reveals a new protease-chaperone machine. Nature. 2002:416:455-9.

11. Marsh JW, Lott WB, Tyndall JDA, Huston WM. Proteolytic activation of Chlamydia trachomatis HtrA is mediated by PDZ1 domain interactions with protease domain loops L3 and LC and beta strand 35 . Cell Mol Biol Lett. 2013;18:522-37.

12. Huston WM, Tyndall JDA, Lott WB, Stansfield SH, Timms P. Unique residues involved in activation of the multitasking protease/chaperone HtrA from Chlamydia trachomatis. PLOS ONE. 2011:6:e24547.

13. Patel $P$, De Boer $L$, Timms $P$, Huston WM. Evidence of a conserved role for Chlamydia HtrA in the replication phase of the chlamydial developmental cycle. Microbes Infect. 2014;16:690-4.

14. Ong VA, Marsh JW, Lawrence A, Allan JA, Timms P, Huston WM. The protease inhibitor J0146 demonstrates a critical role for CtHtrA for Chlamydia trachomatis reversion from penicillin persistence. Front Cell Infect Microbiol. 2013;3:1-10.

15. Gloeckl S, Ong VA, Patel P, Tyndall JDA, Timms P, Beagley KW, et al. Identification of a serine protease inhibitor which causes inclusion vacuole reduction and is lethal to Chlamydia trachomatis. Mol Microbiol. 2013:89:676-89.

16. Huston WM, Theodoropoulos C, Mathews SA, Timms P. Chlamydia trachomatis responds to heat shock, penicillin-induced persistence, and IFN-gamma persistence by altering levels of the extracytoplasmic stress response protease HtrA. BMC Microbiol. 2008:8:1-16.

17. Huston WM, Swedberg JE, Harris JM, Walsh TP, Mathews SA, Timms P. The temperature activated $\mathrm{HtrA}$ protease from pathogen Chlamydia trachomatis acts as both a chaperone and protease at $37^{\circ} \mathrm{C}$. FEBS Lett. 2007;581:3382-6.

18. Gloeckl S, Tyndall JDA, Stansfield SH, Timms P, Huston WM. The active site residue V266 of chlamydial HtrA is critical for substrate binding during both in vitro and in vivo conditions. J Mol Microbiol Biotechnol. 2012;22:10-6.

19. Muschiol S, Bailey L, Gylfe A, Sundin C, Hultenby K, Bergstrom S, et al. A small-molecule inhibitor of type III secretion inhibits different stages of the infectious cycle of Chlamydia trachomatis. Proc Natl Acad Sci U S A. 2006;103:14566-71

20. Kari L, Goheen MM, Randall LB, Taylor LD, Carlson JH, Whitmire WM, et al. Generation of targeted Chlamydia trachomatis null mutants. Proc Natl Acad Sci U S A. 2011;108:7189-93.

21. Nguyen $\mathrm{BD}$, Valdivia $\mathrm{RH}$. Virulence determinants in the obligate intracellular pathogen Chlamydia trachomatis revealed by forward genetic approaches. Proc Natl Acad Sci U S A. 2012;109:1263-8.

22. Wang Y, Kahane S, Cutcliffe LT, Skilton RJ, Lambden PR, Clarke IN. Development of a transformation system for Chlamydia trachomatis: restoration of glycogen biosynthesis by acquisition of a plasmid shuttle vector. PLoS Pathog. 2011;7:e1002258.

23. Kodym A, Afza R. Physical and chemical mutagenesis. Methods Mol Biol. 2003:236:189-204

24. Beare PA, Sandoz KM, Omsland A, Rockey DD, Heinzen RA. Advances in genetic manipulation of obligate intracellular bacterial pathogens. Front Microbiol. 2011;2:1-13.

25. Sega GA. A review of the genetic effects of ethyl methanesulfonate. Mutat Res. 1984;134:113-42.

26. Kokes M, Dunn JD, Granek JA, Nguyen BD, Barker JR, Valdivia RH, et al. Integrating chemical mutagenesis and whole-genome sequencing as a platform for forward and reverse genetic analysis of Chlamydia. Cell Host Microbe. 2015;17:716-25

27. Sturdevant GL, Kari L, Gardner DJ, Olivares-Zavaleta N, Randall LB, Whitmire WM, et al. Frameshift mutations in a single novel virulence factor alter the in vivo pathogenicity of Chlamydia trachomatis for the female murine genital tract. Infect Immun. 2010;78:3660-8. 
28. Merdanovic M, Mamant N, Meltzer M, Poepsel S, Auckenthaler A, Melgaard $R$, et al. Determinants of structural and functional plasticity of a widely conserved protease chaperone complex. Nature. 2010;17:837-43.

29. Lipinska BB, Fayet O, Baird L, Georgopoulos CC. Identification, characterization, and mapping of the Escherichia coli htrA gene, whose product is essential for bacterial growth only at elevated temperatures. J Bacteriol. 1989;171:1574-84.

30. Strauch KL, Beckwith J. An Escherichia coli mutation preventing degradation of abnormal periplasmic proteins. Proc Natl Acad Sci U S A. 1988:85:1576-80.

31. Spiess CC, Beil AA, Ehrmann MM. A temperature-dependent switch from chaperone to protease in a widely conserved heat shock protein. Cell. 1999;97:339-47.

32. Lindahl T, Sedgwick B, Sekiguchi M, Nakabeppu Y. Regulation and expression of the adaptive response to alkylating agents. Annu Rev Biochem. 1988;57:133-57

33. Ge X, Wang R, Ma J, Liu Y, Ezemaduka AN, Chen PR, et al. DegP primarily functions as a protease for the biogenesis of $\beta$-barrel outer membrane proteins in the Gram-negative bacterium Escherichia coli. FEBS J. 2013;281:1226-40

34. Nguyen BD, Valdivia RH. Forward genetic approaches in Chlamydia trachomatis. J Vis Exp. 2013;80:e50636.

35. Huston WM, Gloeckl S, de Boer L, Beagley KW, Timms P. Apoptosis is induced in Chlamydia trachomatis-infected HEp-2 cells by the addition of a combination innate immune activation compounds and the inhibitor wedelolactone. Am J Reprod Immunol. 2010;65:460-5.

36. Myers GSA, Mathews SA, Eppinger M, Mitchell CM, O'Brien KK, White OR, et al. Evidence that human Chlamydia pneumoniae was zoonotically acquired. J Bacteriol. 2009;191:7225-33.

37. Alikhan N, Petty NK, Ben Zakour NL, Beatson SA. BLAST Ring Image Generator (BRIG): simple prokaryote genome comparisons. BMC Genomics. 2011;12:402

\section{Submit your next manuscript to BioMed Central and take full advantage of:}

- Convenient online submission

- Thorough peer review

- No space constraints or color figure charges

- Immediate publication on acceptance

- Inclusion in PubMed, CAS, Scopus and Google Scholar

- Research which is freely available for redistribution 